\title{
Peristiwa- Peristiwa Sejarah dan Karakteristik Masyarakat Jepang dalam Novel Asakusa Bakuto Ichidai Karya Jun'ichi Saga
}

\author{
Ni Wayan Sutarini Ronthi ${ }^{*}$, I Made Sendra ${ }^{2}$, Ida Ayu Laksmita Sari ${ }^{3}$ \\ ${ }^{[123]}$ Program Studi Sastra Jepang Fakultas Ilmu Budaya, Universitas Udayana \\ ${ }^{1}$ [tarironthi36049@gmail.com] ${ }^{2}$ [sendramade65@gmail.com] \\ 3 [dayumita23@gmail.com] \\ *Corresponding Author
}

\begin{abstract}
Abstrak
Penelitian ini berjudul "Peristiwa Sejarah dan Karakteristik Masyarakat Jepang dalam novel Asakusa Bakuto Ichidai Karya Junichi Saga”. Penelitian ini bertujuan untuk mengetahui peristiwa sejarah yang dialami oleh masyarakat Jepang pada zaman Taisho hingga Showa, serta karakteristik masyarakat Jepang yang diceritakan dalam novel Asakusa Bakuto Ichidai. Penelitian ini menggunakan metode deskriptif analisis. Teori yang digunakan adalah sosiologi sastra menurut Laurenson. Berdasarkan hasil analisis, peristiwa sejarah yang dialami masyarakat Jepang dalam novel Asakusa Bakuto Ichidai adalah kerusuhan di pertambangan Ashio, Perang Dunia I, gempa Kanto, mangkatnya Kaisar Taisho, Perang Manchuria, pemberontakan oleh opsir muda, peristiwa Abe Sada, dan Perang Dunia II. Adapun karakteristik masyarakat Jepang yang tercermin dalam novel Asakusa Bakuto Ichidai adalah memiliki kebiasaan menghargai waktu, memiliki semangat juang yang tinggi (ganbaru), tradisi saling memberikan bingkisan (okurimono), memiliki tradisi yang menjaga kepercayaan terhadap ajaran Buddha, masyarakat yang hormat terhadap Kaisar, serta memiliki budaya malu. Berlandaskan karakter yang kuat yaitu memiliki jiwa pekerja keras dan memegang teguh tradisi, diketahui bahwa masyarakat Jepang cepat bangkit dari keterpurukan. Hal tersebut terbukti dari berhasilnya masyarakat Jepang melalui berbagai peristiwa salah satunya adalah Perang Dunia II. Peristiwa Perang Dunia II merupakan peristiwa yang paling berpengaruh bagi masyarakat Jepang ke depannya.
\end{abstract}

Kata Kunci : Peristiwa Sejarah, Karakteristik, Taisho, Showa.

\begin{abstract}
This research, entitled "Historical Events and Characteristic of Japanese Society in Asakusa Bakuto Ichidai Novel by Saga Jun 'Ichi". The aim of this research is recognizing the historical events experienced by the Japanese community during the Taishou to Shouwa period, as well as the characteristics of the Japanese society described in the novel Asakusa Bakuto Ichidai. The research used descriptive method of abstraction. The theory used is the sociology of literature according to Laurenson. Based on the result of the analysis, the historical events experienced by Japanese society in the novel Asakusa Bakuto Ichidai are Ashio riot, World War I, Kanto earthquake, the death of Taishou Emperor, War Manchuria, rebellion by young officer, Abe Sada events, and World War II. The characteristics of Japanese society reflected in the novel Asakusa Bakuto Ichidai are to have a habit of respecting time, high morale (ganbaru), the tradition of giving each other gifts (okurimono), having a tradition that keeps the belief in Buddhism, the people who respect the Emperor, shame culture. Based on the strong character of having a hard-working soul and holding fast to tradition, it is known that the Japanese people quickly rise from adversity. It is proven by the success of Japanese society through
\end{abstract}


various events, one of them is the World War II. The event of World War II is the most influential event for the Japanese society in the future.

Key words : Historical events, Characteristics, Taisou, Shouwa.

\section{Latar Belakang}

Suatu peristiwa yang terjadi pada kehidupan sering menjadi inspirasi terbentuknya suatu karya sastra, karena sastra merupakan refleksi suatu peristiwa yang kemudian dikembangkan oleh penulis ke dalam suatu karya sastra, misalnya dapat berupa cerpen, puisi, bahkan novel. Banyak pesan moral yang dapat disampaikan melalui suatu karya sastra, diantaranya pendidikan, sosial, ekonomi, budaya, bahkan politik.

Novel yang berjudul Asakusa Bakuto Ichidai (浅草博徒一代) karya seorang penulis sekaligus dokter yaitu Junichi Saga merupakan sebuah novel yang memaparkan berbagai peristiwa yang terjadi seperti Gempa Kanto, hingga Perang Dunia II. Salah satu peristiwa besar yang berpengaruh bagi kehidupan masyarakat Jepang pada saat itu adalah gempa besar yang terjadi pada 1 September 1923 di wilayah Kanto yang meliputi Tokyo, Yokohama, dan perfektur-perfektur yang terdapat disekitarnya. Puluhan ribu masyarakat Jepang meninggal pada peristiwa tersebut. Selain itu sebagian besar pabrik-pabrik yang ada di Tokyo dan Yokohama hancur, hal tersebut berdampak buruk pada perekonomian masyarakat pada masa itu (Azhari, 2011:45).

Tidak hanya bidang ekonomi yang mendapat pengaruh dari peristiwaperistiwa yang terjadi sepanjang zaman Taishou (1912-1926) hingga zaman Shouwa (1926-1945). Kehidupan sosial masyarakat juga mendapat pengaruh besar dari peristiwa-peristiwa yang terjadi, hal tersebut berdampak pada perubahan perilaku masyarakat.

\section{Pokok Permasalahan}

Berdasarkan latar belakang yang telah dipaparkan, adapun rumusan masalah adapun rumusan masalah yang dibahas dalam penelitian ini adalah sebagai berikut :

1. Bagaimanakah peristiwa-peristiwa sejarah yang terjadi dalam novel Asakusa Bakuto Ichidai?

2. Bagaimanakah karakteristik masyarakat Jepang dalam novel Asakusa Bakuto Ichidai?

\section{Tujuan Penelitian}

Secara umum tujuan dari penelitian ini adalah dapat bermanfaat bagi pembaca mengenai studi sastra, serta mampu meningkatkan apresiasi terhadap karya sastra Jepang, sehingga dapat dinikmati dan lebih dikenal oleh masyarakat. Tujuan khusus dari penelitian ini yaitu untuk mengetahui serta memahami peristiwa sejarah yang terjadi serta karakteristik masyarakat Jepang dalam novel Asakusa Bakuto Ichidai (浅草博徒一代).

\section{Metode Penelitian}

Pengumpulan data dilakukan dengan studi kepustakaan dengan teknik catat, yaitu dengan cara membaca, memahami, dan mencatat bagian yang diperlukan dalam penelitian. Data-data yang dikumpulkan adalah data-data dari novel Asakusa Bakuto Ichidai (浅草博徒 一代) yang berkaitan dengan peristiwaperistiwa sejarah serta karakteristik masyarakat Jepang. Pada tahap analisis data digunakan metode analisis deskriptif, yaitu dengan cara mendeskripsikan faktafakta yang kemudian dilanjutkan dengan 
menganalisis (Ratna, 2006: 53). Pada tahap penyajian analisis data digunakan metode informal, yaitu penyajian hasil analisis melalui kata-kata, bukan dalam bentuk angka, bagan, atau statistik (Ratna, 2006: 50).

\section{Hasil dan Pembahasan}

Pada bagian ini disajikan hasil analisis data mengenai peristiwa sejarah serta karakteristik masyarakat Jepang dalam novel Asakusa Bakuto Ichidai (浅 草博徒一代) adalah sebagai berikut :

\subsection{Peristiwa Sejarah dalam Novel Asakusa Bakuto Ichidai (浅草博徒 一代)}

Hasil yang didapat dalam analisis penelitian ini adalah peristiwa-peristiwa sejarah pada novel ini diketahui terjadi antara zaman Taisho hingga Showa, yaitu Kerusuhan di Tambang Tembaga Ashio pada tahun 1907, Perang Dunia I, Gempa Kanto, perang di Mancuria sekitar tahun 1931. Peristiwa ini kemudian berefek pada pemberontakan yang dilakukan oleh opsir muda pada tahun 1936 yang lebih dikenal dengan peristiwa 26 Februari 1936. Pada bulan Mei di tahun yang sama terjadi sebuah peristiwa pembunuhan disertai mutilasi yang dilakukan oleh Abe Sada. Lalu Perang Dunia II menjadi peristiwa terakhir yang diketahui melalui novel Asakusa Bakuto

\section{Ichidai (浅草博徒一代).}

Dari berbagai peristiwa yang dialami masyarakat Jepang selama zaman Taisho hingga Showa, Perang Dunia II merupakan peristiwa yang paling berpengaruh pada kehidupan masyarakat pada saat itu, seperti yang terlihat pada data (1) berikut ini :

Data (1)
そうして昭和二十年なったんでした が、戦争はますます激しくなる。空 襲も毎日という有様。

(浅草博徒一代, 1989: 338)

Soushite shouwa ni juи nen nattan deshita ga, sensou wa masu masu-masu hageshiku naru. Kuиshuи mo mai nichi arisama.

Terjemahan:

Hingga tahun 1945 saat keadaan benarbenar sangat berat, dengan terjadinya serangan udara setiap hari.

(Confessions of A Yakuza, 2009: 301)

Pada data (1) dipaparkan mengenai serangan yang yang diterima oleh pihak Jepang pada Perang Dunia II. Tahun 1944 adalah awal mula serangan Amerika Serikat terhadap Jepang dengan melakukan serangan secara besar-besaran dengan pesawat pengebom yang ditujukan pada pulau utama Jepang. Serangan melalui udara hampir terjadi setiap hari hingga tahun 1945. Hal tersebut dilakukan untuk menjatuhkan moral Jepang dan memaksa Jepang untuk menyerah pada Sekutu. Peristiwa tersebut menyebabkan sekitar 100.000 orang meninggal karena terpapar racun dari bom, kekurangan oksigen, atau terbakar hidup-hidup. Selain itu rumah-rumah warga hancur karena sebagian besar terbuat dari kayu, sepuluh mil bagian timur Tokyo hancur dan kurang lebih 250 gedung roboh pada serangan di Tokyo 10 Maret 1945. Sembilan hari kemudian AS kembali membom wilayah Jepang. Kali ini di wilayah Osaka, Nagoya, dan Kobe (Manis, 2013 : 237). 


\subsection{Karakteristik Masyarakat Jepang dalam Novel Asakusa Bakuto Ichidai (浅草博徒一代)}

Konsep On, Giri dan Ninjou yang melekat kuat menjadikan konsep tersebut pondasi dalam melakukan kegiatan sehari-hari bagi masyarakat Jepang. Rasa hutang budi yang timbul membentuk masyarakat Jepang yang bekerja keras dan terus menjaga tradisi yang dimiliki bangsanya dan menjadikan Jepang sebagai salah satu negara yang maju saat ini. Bekerja keras dengan tepat waktu merupakan salah satu prinsip kerja orang Jepang. Dalam diri masyarakat Jepang telah tertanam semangat juang yang tinggi. Mereka selalu menyelipkan katakata penyemangat atau mulai beraktivitas dengan gerakan-gerakan serta mengucapkan kata-kata penyemangat seberti "Ganbatte Kudasai".

Selain itu masyarakat Jepang juga merupakan masyarakat yang sangat menghargai tradisinya. Hal tersebut tercermin dalam novel yaitu saat masyarakat melakukan penghormatan terhadap kaisar yg telah mangkat, serta kepercayaan Budhisme yang tetap bertahan hingga saat ini. Pemberian hadiah (Okurimono) tetap dipertahankan masyarakat Jepang sebagai bentuk ungkapan terimakasih pada saat-saat tertentu seperti tahun baru. Jepang juga memiliki budaya yang unik yaitu budaya malu (Haji no Bunka) yang bertahan hingga kini. Pada data (2) dipaparkan mengenai budaya malu masyarakat Jepang yang terdapat dalam novel Asakusa Bakuto Ichidai (浅草博徒一代):

Data (2)

ところがそこが乞食と違うところで、 道に落ちているものだの食堂の残飯 だのは絶対にたべない。仮に我慢が
できなくつて食べるような者がいる と、「ああ、あいつは駄目だ、とう とう乞食になりやがった。唵は死ん だって残飯なんか食わねえ」なんて 意気がっている。(浅草博徒一代, 1989: 57)

Tokoro ga soko ga kojiki to chigau tokoro de, michi ni ochite iru monoda no shokudou no zanpanda no wa zettai ni tabenai. Karini gaman ga dekinakutte taberu youna mono ga iru to, 'aa, aitsu wa dameda, toutou kojiki ni nariya gatta. On wa shin datte zanpan nanka kuwanee' nante iki gatte iru.

Terjemahan:

Tetapi mereka tidak ingin menjadi pemulung, mereka tidak mau memungut apapun yang ada di jalan, atau mengambil sisa-sisa makanan di warung. Siapa yang menyerah dan melakukan hal tersebut akan diejek karena telah menjadi pengemis. Kata mereka "lebih baik aku mati daripada memakan sisa-sisa orang lain".

(Confessions of A Yakuza, 2009: 52)

Pada data (2) menceritakan tentang para buruh yang memilih tetap bertahan dan tidak akan mengambil makanan sisa dari orang lain. Hal tersebut mereka lakukan untuk menghindari rasa malu yang timbul apabila nantinya orang-orang akan mencemooh sikap mereka.

Menurut Benedict (1989 : 338) malu muncul akibat dari ketidak mampuan seseorang membalas budi dari orang lain $(O n)$ yang terdiri dari Giri dan Gimu, serta karena adanya penilaian dari pihak lain yang bersifat negatif seperti kritikan, sindiran, atau cemoohan. Rasa malu yang timbul pada masyarakat Jepang ini bukan karena keberadaan 
Tuhan atau takut berbuat dosa. Masyarakat Jepang menjadikan rasa malu tersebut sebagai tolak ukur atau standar baik buruknya suatu tindakan seseorang, dan pihak yang menjadi penilainya adalah diri sendiri dan masyarakat. Menurut paham Shintoisme dan Budhisme mengajarkan bahwa nilai yang paling tinggi adalah rasa malu. Sehingga menyebabkan aktivitas masyarakat lebih terfokus pada usaha untuk menjaga rasa malu tersebut. Bahkan seseorang dapat dikatakan sebagai orang yang terhormat apabila orang tersebut tahu malu.

Walapun memiliki karakter positif yang kuat, akibat dari berbagai peristiwa serta tuntutan untuk bertahan hidup masyarakat Jepang juga menunjukkan karakter negatif, diantaranya : pekerja kapal hitam, perjudian, wanita penghibur, serta cara bertahan hidup masyarakat Jepang. Karakter negatif tersebut adalah bentuk cara bertahan untuk hidup yang dilakukan oleh masyarakat Jepang dalam kondisi tertentu. Data mengenai karakteristik masyarakat Jepang yang bersifat negatif akibat dari sebuah peristiwa dan merupakan bentuk dari cara bertahan hidup adalah sebagai berikut:

Data (3)

それが今はこんあ姿になっていると いうのは、なぜかというと、金のせ いです。かねを持っていなければ死 んでから後も身を剥がれるなんてこ とはなかったろうに、まあ、金がな くって、かえって身軽になったかも しれません。

(浅草博徒一代, 1989: 103)

Sore ga ima wa kon a sugata ni natte iru to iu no wa, naze ka to iu to, kin no sei desu. Kane o motte inakereba shinde kara nochi mo mi o hagareru nante koto wa nakatta rou ni, maa, kin ga nakutte, kaette migaru ni natta kamo shiremasen.

Terjemahan:

Mereka tidak akan berakhir seperti itu jika bukan karena uang. Bila uang itu tidak ada, mereka tidak akan diusik seperti itu setelah kematiannya, tidak perlu ditarik-tarik hingga terpisah seperti itu.

(Confessions of A Yakuza, 2009: 100)

Pada kutipan data menceritakan saat Eiji dan Kenkichi berusaha mengambil uang yang dibawa oleh seorang ibu yang ia selipkan pada pakaiannya. Peristiwa ini terjadi beberapa saat setelah Gempa Kanto terjadi. Dalam hati Eiji merasa berdosa karena berusaha mengambil dengan paksa uang yang bukan haknya. Menarik dan memisahkan tubuh ibu dan anak yang meninggal karena terbakar saat kebakaran akibat dari Gempa Kanto, ia merasa anak tersebut menatapnya.

Data tersebut menunjukkan bagaimana perilaku seseorang dapat berubah karna faktor lingkungan. Salah satunya adalah faktor ekonomi, pada saat terjadi gempa Kanto orang-orang menyelamatkan diri mereka masingmasing tanpa memperdulikan lingkungan sekitar ataupun materi yang dapat diselamatkan. Pada data ini Kenkichi meminta Eiji menarik paksa dan memisahkan seorang ibu dengan anaknya agar mereka dapat mengambil uang yang dibawa oleh wanita tersebut. Dalam hal ini, kebutuhan untuk bertahan hidup dapat mendorong seseorang berperilaku yang menyimpang khususnya bagi masyarakat Jepang yang terkenal dengan Haji Bunka (budaya malu) serta Tsumi (perasaan bersalah) yang sangat dijunjung tinggi masyarakatnya. 


\section{Simpulan}

Dari berbagai peristiwa yang dialami masyarakat Jepang selama zaman Taisho hingga Showa, Perang Dunia II merupakan peristiwa yang paling berpengaruh pada kehidupan masyarakat pada saat itu. Selain itu dalam novel Asakusa Bakuto Ichidai (浅草博徒一代) dapat terlihat karakter masyarakat Jepang yang bersifat positif dan negatif.

Adapun karakteristik masyarakat Jepang yang bersifat positif diantaranya menghargai waktu, memiliki semangat juang yang tinggi (Ganbaru), menjaga tradisi seperti masyarakat melakukan penghormatan terhadap kaisar yang telah mangkat, kepercayaan Budhisme yang tetap bertahan hingga saat ini serta pemberian hadiah (Okurimono.), dan budaya malu (Haji Bunka). Selain itu adapun karakteristik yang bersifat negatif diantaranya : pekerja kapal hitam, perjudian, wanita penghibur, serta cara bertahan hidup masyarakat Jepang. Karakter negatif tersebut adalah bentuk cara bertahan untuk hidup yang dilakukan oleh masyarakat Jepang dalam kondisi tertentu.

\section{Daftar Pustaka}

Azhari, A.A. 2011. Ganbatte Meneladani Karakter Tangguh Bangsa Jepang. Bandung : Grafindo.

Manis, Hoeda. 2013. Buku Pintar Sejarah dan Pengetahuan Dunia Abad 20. Jogjakarta : Trans Idea Publishing.

Ratna, Nyoman Kutha. 2006. Metode dan Teknik Penelitian Sastra.Yogyakarta : Pustaka Pelajar.

Saga, Jun'ichi. 1991. Asakusa Bakuto Ichidai. Japan : Chikuma Sobo 